Revista Temas Socio Jurídicos

Vol. $36 \mathrm{~N}^{\circ} 73$ Julio - Diciembre de 2017

pp. $81-112$

ISSN 0120-8578

ISSN electrónico: 2590-8901

\title{
EL CONTROL GUBERNAMENTAL EN EL SECTOR PÚBLICO
}

\author{
Eduardo Díaz Ocampo* \\ Recibido: Febrero 21 de 2017 \\ Aprobado: Julio 23 de 2017
}

\section{RESUMEN}

El sistema nacional de control es un conjunto de órganos de control, normas, métodos y procedimientos, estructurados e integrados funcionalmente con el objetivo de conducir y desarrollar el ejercicio del control gubernamental en todas las instituciones públicas de una nación. $\mathrm{Su}$ actuación comprende a todas las actividades y acciones en los campos administrativo, presupuestal, operativo y financiero de las entidades públicas, y del personal que presta servicios en estas, independientemente del régimen que las regule. La Contraloría General de la República, es el ente técnico rector del Sistema de Control, dotado de facultades para supervisar la legalidad de la ejecución del presupuesto del Estado, de la deuda pública y de los actos de las instituciones sujetas a control. Tiene como misión dirigir y supervisar el control gubernamental con eficiencia y eficacia, orientando su accionar al fortalecimiento y transparencia de la gestión de las entidades, así como promover valores y la responsabilidad en los funcionarios y servidores públicos.

\footnotetext{
* Eduardo Díaz Ocampo, Licenciado en Ciencias de la Educación. Licenciado en Ciencias Económicas, Políticas y Sociales. Abogado de los Tribunales de la República del Ecuador. Doctor en Jurisprudencia. Magíster en Desarrollo Curricular. Profesor de Derecho Laboral y Derecho Constitucional. Rector de la Universidad Técnica Estatal de Quevedo, Ecuador. El artículo es parte del proyecto de investigación que se realiza en los estudios de Especialidad vinculados al Control Gubernamental del sector público en la República delEcuador.2016.Email: ediaz@uteq.edu.ec
} 
Palabras claves: control, funcionario público, responsabilidad, servidor público, medios personales.

\title{
GOVERNMENT CONTROL IN THE PUBLIC SECTOR
}

\begin{abstract}
The national system of control is a set of organs of control, legal rules, methods and procedures, structured and integrated functionally with the aim to conduct and develop the exercise of the government control in all the public institutions of a nation. Its performance includes all activities and actions in the administrative, budgetary, operational and financial fields of public entities, and the staff that provides services in these entities, independently of the regime that regulates them. The Comptroller General of the Republic is the technical governing entity of the system of Control, provided with faculties to supervise the legality of the execution of the State's budget, national debt and of the acts of the institutions subject to control. Its mission is to direct and supervise government control with efficiency and effectiveness, directing its actions to strengthen and transparency of the management of the entities, as well as promoting values and responsibility in public official.
\end{abstract}

Key Words: control, public official, responsibility, public servant.

\section{CONTROLE DO GOVERNO NO SECTOR PÚBLICO}

\section{RESUMO}

O sistema nacional de controle é um conjunto de órgãos de controle, normas, métodos e procedimentos, estruturados e integrados funcionalmente com o objetivo de conduzir e desenvolver o exercício do controle governamental em todas as instituições públicas de uma nação. $\mathrm{O}$ seu desempenho inclui todas as atividades e ações nos campos administrativo, orçamentário, operacional e financeiro das entidades públicas, e do pessoal que presta serviços nestas, independentemente do regime que as regula. A Controladoria Geral da República é a entidade técnica governante do Sistema de Controle, dotado de poderes para supervisionar a legalidade da execução do orçamento do Estado, a dívida pública e os atos das instituições sujeitos a controle. Sua missão é dirigir e supervisionar o controle governamental de forma eficiente e efetiva, direcionando suas ações para fortalecer e transparentar a gestão das entidades, bem como promover valores e responsabilidades em funcionários e servidores públicos. 
Palavras-chave: controle, funcionário público, responsabilidade, servidor público, meios pessoais.

\section{EXORDIO}

El comienzo de la Administración se sitúa en el momento en que el poder soberano sobrepasa su materialización en la posición del patrimonio y en los derechos de soberanía, subjetivizándose en la ejecución de los cometidos estatales. En el mundo del esclavismo no existió una administración pública. La lucha entre el príncipe y los estamentos divinos constituyen la monarquía absoluta, que se caracteriza por el arbitrario uso que el monarca hacía de su poder cada vez mayor.

Al transcurrir los años se presentaron nuevas realidades sociales, determinadas por el progreso técnico. Nace en cuanto a la administración la obligación de diversificar sus actividades, fomenta y estima la actividad privada para que actúe a ese fin. La creación de bienes materiales, la gestión económica afrontada por las transformaciones sociales, constituye la tarea que sólo alcanza su verdadera dimensión y se logra plenamente cuando el Estado hace desaparecer el sistema capitalista y los trabajadores asumen el poder.

El Derecho Administrativo, se considera como rama jurídica que fija los principios y analiza las normas que orientan y regulan las relaciones sociales que se producen en la organización y en la actividad de la Administración del Estado, considerada en todas sus esferas tanto nacional como local, siendo el eje central en este ensayo de abundar en los medios personales dentro del actuar de la Administración Pública.

La ordenación jurídica de sus medios personales adquiere singular valor, puesto que la Administración Pública, como ente inmaterial, trasluce su voluntad mediante los actos del personal a su servicio, personas físicas que manifiestan el ejercicio de las potestades del Estado, siendo los titulares de los cargos públicos. Se justiprecia que la heterogeneidad de los servidores públicos -que puede observarse en las disímiles tipologías del personal al servicio del aparato público en las diferentes disposiciones que rigen en un país-, y la diversidad de conceptos de funcionarios públicos que han introducido los legisladores al conceptualizarlos según la finalidad perseguida en las distintas ramas del Derecho, han provocado que este concepto y el régimen jurídico aplicable a esta figura hayan requerido de constantes actualizaciones en el desarrollo histórico. 
No existe un sistema de función pública uniforme, de aplicación general en el mundo. Los sistemas están determinados y condicionados a un momento histórico concreto definido, en el que las condiciones sociales, políticas, económicas y culturales de una sociedad resultan, cuanto menos, distintivas. Dos son los conocidos sistemas clásicos de función pública: sistema cerrado y sistema abierto. Sin embargo, en la actualidad ninguno de estos sistemas se aplica de modo puro con todos sus presupuestos en un diseño de función pública nacional. Hoy, la estructura de la Administración Pública y las relaciones que esta establece con sus medios personales, resultan mucho más complejas que las de los siglos XIX y principios del XX.

El análisis teórico y exegético del concepto de funcionario público en este contexto resulta de suma importancia, máxime cuando los modelos clásicos de función pública se acercan y relacionan cada vez más, conformando en cada país un sistema de función pública sui generis. Cuando en Europa este tema parecía haber quedado saldado a mediados del siglo XX, incontables debates doctrinales se han generado a finales de este e inicios del siglo XXI, precisamente como resultado de los cambios en los fundamentos básicos de la función pública, que también se han extendido a América Latina.

PALOMAR OLMEDA, define su contenido como "...el complejo organizativo que componen las instituciones públicas, en particular la Administración Pública, animado por un conjunto muy numeroso de personas fisicas que en ella trabajan constituyendo la organización pública, estas personas físicas serán los empleados públicos y su conjunto, la función pública..." y agrega, además: "son los encargados de reglamentar, dirigir, ejecutar, asesorar y prestar servicios materiales".

El autor consultado enmarca la función pública en el sistema de órganos y empleados -entendido este último concepto en sentido amplio- de la Administración Pública, así como en un grupo específico de acciones asignadas, obviando los efectos que pueden producir sus actos en la esfera externa de la Administración, es decir, la actividad de servicio que también prestan esos órganos, cuyo contenido también está fijado en la función pública ${ }^{1}$. Partiendo del objetivo general del ensayo jurídico, proponemos: Caracterizar en el plano histórico y doctrinal la evolución que ha tenido la categoría de funcionario público y la responsabilidad de

1 PAlOMAR OLMEDA, Alberto, Derecho de la Función Pública, $4^{\text {ta }}$ Edición, Editorial Dykinson, Barcelona, 1997, p.17. 
su actuar para la Administración Pública, a partir de su asidero jurídico en el ordenamiento jurídico ecuatoriano. Para el logro de esta meta investigativa, fueron utilizados métodos como el jurídico-doctrinal, el histórico-jurídico, y el análisis- jurídico. Lo que nos permitirá arribar a conclusiones.

\section{LA RESPONSABILIDAD DE LOS SERVIDORES PÚBLICOS}

No se podría profundizar en los estudios del Derecho Administrativo si no se tienen claros los conceptos de control y de responsabilidad. El segundo es consecuencia del primero, porque en la Administración Pública debe haber controles establecidos en leyes y reglamentos para lograr que los recursos públicos (económicos, financieros, materiales y humanos) sean bien utilizados, logrando que constituyan una inversión y ahorro, mas no un gasto o pérdida para el Estado, que para el autor de este ensayo están vinculados al principio de legalidad.

Por ello, el control en sí es uno de los elementos que integran y definen el Estado de Derecho y el Estado democrático. Desde una perspectiva conceptual, este control no es más que la actividad de "comprobación, inspección, fiscalización, e intervención", lo que en el ámbito jurídico se expresaría en "un acto o procedimiento por medio del cual una persona o un órgano debidamente autorizado para ello examina o fiscaliza un acto realizado por otra persona u órgano, a fin de verificar si en la preparación y cumplimiento de dicho acto se han observado todos los requisitos que exige la ley".

La doctrina consultada señala que el concepto del control constituye uno de los paradigmas de la democracia incorporada al Estado, y la norma jurídica, límite del control de poder, lo hace susceptible de su verificación, por lo que es sustancial en la democracia. Por ello, el Derecho es un elemento difícil de conceptualizar; a partir de su etimología se constata que existen diversas palabras que le definen como: rectus, directius, justitia, jus, juris, rectum, aequm, atis, todas ellas refieren derecho, recto, justicia, equidad, etc. Ya en Roma se le señalaba como ars boni et aequi.

KELSEN lo definió como un orden coactivo de la conducta humana ${ }^{2}$. GARCÍA MÁYNEZ, considera que es un conjunto de normas imperoatributivas que en cierto momento histórico y en un determinado 
territorio, quienes detentan el poder juzgan obligatorias para el resto de la colectividad ${ }^{3}$.

DWORKIN estimó que el Derecho es un concepto interpretativo ${ }^{4}$. Desde la perspectiva de la Sociología, se analiza lo que señala LASALLE, quien consideró que la Constitución es la suma de factores reales de poder que se trocan en factores jurídicos; para este autor consultado, el derecho es la suma de los factores reales del poder.

La etimología latina le define desde la época medieval como contra rotulum, en Francia se le consideró como contre-lore (contralibro) -libro registro-, término que con el trascurrir del tiempo se popularizó hasta precisarlo con las definiciones de fiscalizar, dominar, someter, etc.

El catedrático CABANELLAS consideró que el término de control es mejor reconocerle como comprobación, fiscalización, intervención, registro, vigilancia, mando, gobierno, predominio, hegemonía, supremacía, dirección, guía, freno, contención, regulador, factor, causa ${ }^{6}$.

MÁRQUEZ GÓMEZ nos dice que: [...] en la doctrina jurídica se entiende por control la actividad de carácter registral o técnica encomendada a una función pública, un ente administrativo estatal o a un empleado público, por el orden jurídico, que se dirige a revisar la adecuación y legalidad de los actos encomendados a los diversos órganos del poder público, con la obligación de pronunciarse sobre ellos?.

Su naturaleza jurídica está concebida a partir de que el control es un sistema de verificación y corrección de la legalidad, que evalúa el principio de juridicidad, está directamente vinculado al concepto de Estado de Derecho, y, ciertamente, se relaciona asimismo con la democracia como forma política de gobierno nacional.

Sus características son: está requerido para su ejercicio de la independencia necesaria que le otorga el modelo democrático, traducido en una serie de garantías como independencia, objetividad

3 GARCÍA MÁYNEZ, Eduardo, Introducción al estudio del Derecho, 41ª edición, Editorial Porrúa, México, 1990, p.37.

4 DWORKIN, Ronald, El imperio de la Justicia, Editorial Gedisa, España, 1988, pp.72, 287-288.

5 LASALLE, Ferdinand, ¿Qué es una Constitución?, Editorial Panamericana, Colombia, 2002,pp.14-15.

6 CABANELLAS DE TORRES, Guillermo, Diccionario Jurídico Elemental, $11^{\text {na }}$ edición, Editorial Heliasta S.R.L., España, 1993.

7 MÁRQUEZ GÓMEZ, Daniel, Los procedimientos Administrativos materialmente jurisdiccionales como medios de control en la Administración Pública, Universidad Nacional Autónoma de México, México, 2002; GIMÉNEZ ICARRONS, Eugenia, Los controles administrativos sobre los entes locales, Generalitat de Catalunya, Institut d'Estudis Autonómics-Marcial Pons, Editorial Jurídicas y Sociales S.A, Madrid, 2001. 
y respeto para la realización de esta labor. El control administrativo se ejerce siempre por una autoridad perteneciente a la administración activa, puede ser activado en forma espontánea por la propia autoridad administrativa o puede ser provocado mediante la interposición de un recurso. Este control tiene por objeto revisar la legalidad o la oportunidad del acto sometido a examen. La Administración Pública, en principio, puede revocar o modificar, nulificar o anular sus propios actos o actos de sus funcionarios subordinados, siempre y cuando estos actos no contengan un beneficio o resultado favorable, pues esta clase de actos, para su revocación, requieren de la intervención jurisdiccional vía acción de lesividad en el juicio contencioso administrativo. El control administrativo no se encuentra sometido a las reglas del procedimientojurisdiccional.

Sus elementos: el sujeto activo será el órgano de autoridad controladora, es decir, aquel ente público que ejerce el control (Contralorías, órganos de inspección) El sujeto pasivo, el cual es, en principio una entidad pública (sea de la Administración centralizada o paraestatal, incluso los organismos autónomos); sin embargo, tanto en ley como en las prácticas modernas de los sistemas de control administrativo, se ha establecido que también son sujetos de control los funcionarios públicos en lo específico, en relación con sus atribuciones directas.

El objeto: se determina de tres maneras, de legalidad, de oportunidad y de gestión. La forma de los controles administrativos resulta variada, pues son el conjunto de mecanismos, vías, técnicas, métodos, sistemas y procedimientos, los cuales pueden surgir de distintos documentos, tales como la Ley y sus Reglamentos, Acuerdos Administrativos, Circulares, Lineamientos de carácter general para la Administración Pública, por citar algunos; y sus características y requisitos de validez variarán, sobretodo en virtud de la naturaleza del acto u operación sujeta al control.

Desde una perspectiva teleológica, la finalidad del control administrativo, es garantizar una actuación regular, equilibrada, eficaz y honesta de los entes públicos y los funcionarios adscritos a ellos, a fin de cumplir adecuadamente con sus funciones y estar en aptitud de satisfacer las necesidades colectivas del Estado.

Por ello, luego del análisis de sus elementos, el control es un mecanismo de contención para la extralimitación en el uso de los poderes públicos, que se constituye en un amparo para los administrados. En el marco de 
un Estado de Derecho, implica que la Administración, en su organización, funcionamiento, relaciones con la comunidad y su personal, están subordinados al ordenamiento jurídico, el que deriva directamente de un marco constitucional. Las normas jurídicas deben someterse a la Constitución Política, y a éstas deberán someterse, a su vez, las normas que derivan de la potestad reglamentaria ${ }^{8}$.

Entonces, para el autor de este ensayo, el control no es más que el vehículo efectivo de la limitación del poder, considerando dentro de éste a todas las formas e instrumentos que posee el sistema político y jurídico para supervisar el ejercicio de los poderes públicos; se expresa en actos o normas a partir del texto constitucional, entendiendo que estas últimas son una expresión precisamente de su actividad jurídica por medio del desarrollo normativo, el mismo es ejecutado por la Administración Pública mediante los órganos que la misma les otorga este ejercicio del poder público.

El Derecho, analizado desde la perspectiva del control, es considerado como una herramienta y a la vez una técnica. Es instrumental, toda vez que juridifica las conductas impuestas como obligatorias a los agentes sociales, en especial a los agentes de la sociedad, en particular a sus servidores públicos, al imponerles márgenes de actuación que los convierte en sujetos obligados y, por ende, en objetivos de control por excelencia. Como técnica, el derecho delimita los procesos, métodos y formas de actuación de los entes controlados cuando estos ejecutan sus actividades, al decir de MÁRQUEZ GÓMEZ9.

Cuando los controles en el manejo de los recursos públicos están bien definidos y ejecutados, se consigue generación efectiva de riquezas. Estos controles están presentes antes, durante y después de la ejecución de un acto o de un contrato administrativo, ejerciéndose en el Ecuador por medio de las Instituciones Superiores de Control (Contraloría General del Estado, Procuraduría General del Estado, Ministerio Público, Comisión de Control Cívico de la Corrupción y Superintendencias). De los resultados de los controles ejercidos nace la determinación de las responsabilidades para todos aquellos que administren los recursos públicos, así como para terceros que tienen relación directa o indirecta con tal administración.

8 CAGNONI, José, Introducción a la Teoría del Control, Editorial Universidad de Montevideo, Uruguay, 1996.

9 MÁRQUEZ GÓMEZ, Daniel, Función jurídica del control de la Administración Pública, serie doctrina jurídica, número 242, Instituto de Investigaciones Jurídicas-UNAM, México, 2005, pp.5-48; SÁNCHEZ MORÓN, Miguel, El control de las Administraciones Públicas y sus problemas, Editorial Espasa- Calpe S.A, Madrid, 1991. 
Por todo lo analizado, se define que el control gubernamental es el que se dirige fundamentalmente a evaluar la situación de indicadores $\mathbf{u}$ objetivos específicos de interés para el país en el momento del control, profundizando en los aspectos más problemáticos, según las particularidades de cada entidad de la Administración Pública. El cumplimiento de las funciones estatales que le han sido encomendadas al organismo controlado, compulsando el control ramal o sectorial. El cumplimiento de las funciones privadas encomendadas por las políticas públicas. Los resultados productivos y de su gestión económica, promoviendo el control interno.

No obstante, este autor considera a partir de la sistematización de sus elementos que definen al control gubernamental, es memorable significar que es la verificación por comisiones de trabajo que se constituyen a tales efectos con la participación de entidades de la Administración Central del Estado. Permite evaluar el cumplimiento de la aplicación de las políticas de gobierno y el cumplimiento del plan y el presupuesto por los organismos de la Administración del Estado y por las entidades de su sistema bajo el principio de legalidad; este control gubernamental se ejecuta acorde con un plan con una periodicidad anual, incluye en esta evaluación el seguimiento a los realizados en años anteriores. En sí, este implica la supervisión, vigilancia y verificación de los actos y resultados de la gestión pública, en atención al grado de eficiencia, eficacia, transparencia y economía en el uso y destino de los recursos y bienes del Estado, así como del cumplimiento de las normas legales y de los lineamientos de política y planes de acción, evaluando los sistemas de administración, gerencia y control con fines de su mejoramiento, mediante la adopción de acciones preventivas y correctivas pertinentes. El control gubernamental es interno y externo. Su desarrollo constituye un proceso integral y permanente.

\section{LA ADMINISTRACIÓN PÚBLICA Y SUS MEDIOS PERSONALES}

Para establecer una relación entre la Administración Pública y sus medios personales debemos partir de que esta es un ente inmaterial, una estructura dinámica conformada por un sistema de órganos -se encuentra condicionada a la historia, tradiciones y tendencias políticas del Estado-. Órganos que tienen atribuidas por ley determinadas competencias para realizar funciones con fines públicos. Pero como ente inmaterial para actuar en el mundo del Derecho, requiere de personas físicas idóneas por 
medio de las cuales manifestar su voluntad, ejecutar acciones concretas y prestar sus servicios como vehículo para lograr sus fines ${ }^{10}$.

Estas personas físicas establecen una relación especial con la Administración Pública, al incorporarse a ella formando parte íntegral de su organización. Están sometidos a un régimen especial de Derecho Público que alcanza los modos de ingreso a la Administración Pública, derechos y deberes, responsabilidad, así como los mecanismos de extinción de dicha relación, y son conocidos bajo la categoría de funcionarios públicos. Los funcionarios públicos se encuentran unidos a la Administración Pública en una doble relación: de servicio, al someterse al conjunto de normas que rigen su actuación; de prestación, en no pocos casos con carácter patrimonial y otra orgánica, al ser el titular de un cargo a fin de producir efectos en el mundo jurídico, sea en el ámbito externo o interno de la Administración Pública ${ }^{11}$.

$\mathrm{Al}$ aplicar un análisis etimológico, el término funcionario proviene del latín fungor, que significa hacer, cumplir o ejecutar en sentido dinámico. Lo que infiere la acción u omisión realizada por una persona física con resultados objetivos en la realidad; resultados que, al agregarle la categoría de público, presupone que esa actuación se realiza con fines de interés para la colectividad ${ }^{12}$.

El concepto de funcionario público, ha sido considerado como uno de los más difíciles de definir por la doctrina administrativista dada su imprecisión, derivada, en primera instancia, por la heterogeneidad de servidores públicos, como se observa en la tipología del personal funcionario en diferentes disposiciones que rigen en un país, así como por la diversidad de conceptos de funcionarios al servicio de la Administración Pública, utilizados en las distintas ramas del Derecho, lo

10 Ver lo que apunta al respecto SANTAMARÍA PASTOR, Juan, Principios de Derecho Administrativo
General, Tomo I, Editorial Iustel, $2^{\text {da }}$ Edición, Madrid, 2003, pp. 641-642.
11La integración entre el funcionario público y la Administración Pública, se han elaboraron distintas
concepciones, entre las más conocidas, las llamadas teorías del mandato y de la representación. La teoría del
mandato intentó solucionar el problema del procedimiento de imputación de la voluntad de la persona física a
la correspondiente a la persona moral acudiendo a esa institución jurídica, sobre la base que las personas
físicas actuaban como mandatarios de la persona jurídica. Pero esta concepción se reveló muy pronto como
insuficiente en la medida en que ella supone postular que la persona moral pueda declarar su voluntad de
antemano, al otorgar ese mandato, presuponiendo lo que se pretende explicar a través del procedimiento de
imputación. Al resultar esa tesis inadecuada, se acudió a la teoría de la representación legal que, respecto de
las personas jurídicas, se pretendía que ejercían las personas físicas. En tal sentido, no puede explicar cómo es
el propio Estado quien designa su representante legal, ya que, si la representación presupone la existencia de
dos voluntades, sería imposible al Estado designar su representante, pues él carece en ese momento de
voluntad. Sobre este tema consultar a OYANGUREN, Armando, Manual elemental de Derecho
Administrativo, Editorial Universitaria de la UNAN, Nicaragua, 1992, pp.196 y ss.
DE MIGUEL, Raimundo, Diccionario etimológico latino-español, 23 edición, Madrid, 1974.
12 BIELSA, Rafael, Derecho Administrativo, Tomo II, Editorial Depalma, Buenos Aires, 1956, pp.14 y ss; 
que significa la inexistencia de un concepto unitario de funcionario público en un ordenamiento jurídico.

A pesar de no existir un concepto unitario de funcionario público válido para todos los países, y conociendo que en cada país existen diversos conceptos de este, podemos afirmar que esa definición está ligada al Estado, condicionado a su historia y a su legislación. Definir esta figura jurídica presupone buscar elementos comunes que caractericen la noción, las bases conceptuales de funcionario público y no pocos han sido los intentos de la doctrina.

No obstante, entre los teóricos de América Latina en Derecho Administrativo que han abordado la función pública con singular importancia está BIELSA, que al referirse al funcionario público expresó: "En sentido amplio es toda persona que realice o contribuya a que se lleven a cabo funciones esenciales y específicas del Estado es decir, fines públicos propios del mismo....", de este modo, ubica el centro de atención en la realización o cumplimiento de funciones esenciales o propias de la Administración, no importa el modo de ingreso y en sentido estricto, exacerba la prestación de servicios públicos como elemento esencial de la definición; en este sentido creemos, como apunta MARIENHOFF, que la función de los funcionarios públicos no puede confundirse solo con el servicio público, sino como expresión normal de la actividad de la Administración Pública ${ }^{13}$.

\section{LA RESPONSABILIDAD DEL FUNCIONARIO PÚBLICO}

Partiendo del hecho de que el funcionario público, al estar subordinado a un régimen de Derecho Público, se somete a una situación legal y reglamentaria, en la cual sus derechos y deberes están definidos por reglas impersonales y generales que pueden ser modificadas por el Estado en cualquier momento siempre sin efectos retroactivos, resulta entonces que las condiciones de empleo no pueden ser objeto de convenciones, incluso su nombramiento no tiene carácter contractual, sino que es un acto requerido de coadyuvante que implica la aplicación al interesado del conjunto de normas que regulan su función.

El hecho de estar incorporado a la Administración Pública mediante los mecanismos tradicionales de nombramiento o elección como requisito esencial, no limita que el concepto de funcionario comprenda solamente la actividad del funcionario de iure sino también al de facto.

13 BIELSA, Rafael, Los agentes de la Administración Pública, funcionarios y empleados, Editorial Roque de Palma, Buenos Aires, 1956. 
Este autor del ensayo, considera que los funcionarios políticos son los que están ligados a la autoridad ideológica y partidista, con determinadas obligaciones en la Administración Pública respecto de su dirección política; pueden ser electos o nombrados, igual que los funcionarios públicos, y aseguran de modo directo y eficaz el desarrollo y ejecución de una política. Pero al definir entonces responsabilidad, partiremos desde el vocablo en sí, que tiene múltiples acepciones, entre las que encontramos: cualidad de responsable, cargo u obligación moral que resulta para alguien del posible error en cosa o asunto determinado, capacidad existente en todo sujeto activo de derecho para reconocer y aceptar las consecuencias de un hecho realizado libremente.

Pero la definición que más nos interesa en este estudio es la responsabilidad en sentido jurídico, que puede ser definida como una deuda, obligación de reparar y satisfacer, por sí o por otra persona, a consecuencia de un delito, de una culpa o de otra causa legal. Es preciso detenernos un poco y observar el desarrollo de la responsabilidad en los distintos ordenamientos jurídicos. En un primer momento la responsabilidad obedecía a un régimen objetivo, el que encontramos inmerso en el Derecho Romano mediante diversos cuerpos legales como la Ley del Talión ${ }^{14}$, que pretendía el desarrollo de una justicia retributiva, donde la pena asignada al victimario no era equivalente al delito, sino que era idéntica a él.

Posteriormente surgirá la composición como una sanción distinta, ya que no atacaba a la persona del victimario, sino a su patrimonio y consistía en el pago de una indemnización de perjuicios, que con el transcurso del tiempo adquiría un carácter legal. Por último encontramos la Ley de las XII Tablas, la cual corresponde a una ley mixta, ya que aplica en algunos casos la Ley del Talión y en otros la composición.

Todo esto cambiaría en la Edad Media, cuando se consideró al Derecho no como la cosa justa, sino como un conjunto de normas de conducta. El Derecho adquiere un alto grado de moralidad religiosa, por lo que el individuo, al responder por la inmoralidad de su acto, responde ante Dios porque ha cometido un pecado.

Es en ésta época que surge el régimen subjetivo de responsabilidad, que hace referencia a las nociones de culpa y dolo del sujeto. Conceptualmente es admisible la existencia de una responsabilidad

14 La Ley del Talión sirvió como inspiración de varios cuerpos legales de la antigüedad, como el Código de Hammurabi, el Derecho Hebreo y las Leyes de Manú (India). 
objetiva- por no decir que ella corresponde a la auténtica responsabilidad (género), debiendo constituir la regla general, de la cual la responsabilidad subjetiva (especie) es la regla particular y no al revés, como sucede hoy...

Estas responsabilidades están previstas en la Constitución Política, en la Ley y en el Reglamento respectivo, con sus consecuentes grados de culpabilidad y sanciones, siendo las normas que rigen esta materia la Ley Orgánica de la Contraloría General del Estado y el Reglamento de Responsabilidades en Ecuador. El Estado también es ente de responsabilidad frente a sus habitantes, como lo consagra la Constitución en su artículo 20, obligándolo a indemnizar a los particulares por los daños ocasionados debido a la insuficiente prestación de servicios públicos o de los actos de sus servidores en el desempeño de sus cargos. Esta obligación Estatal tuvo su nacimiento en la Revolución Francesa, cuando el concepto de soberanía se transfirió del Rey absolutista al pueblo. Desde entonces, nada excusa al Estado de su responsabilidad directa frente a sus contribuyentes y ciudadanos en general.

Respecto de las concepciones del servicio público, DUGUIT propuso la máxima dimensión del mismo, por considerarlo como toda actividad que deba ser asegurada, reglada y controlada por los gobernantes. Esta idea conllevó en su momento a una nueva concepción del Estado, fundada en la idea del servicio público, donde la esencia del poder político no es el ejercicio de la soberanía o de la autoridad inherente a ella, sino el servicio a los ciudadanos -Estado de Bienestar Social-. En tanto el funcionario público ostenta poderes y prerrogativas en la medida en que es un servidor público y la legitimidad de su actuación se mide en función de esa finalidad ${ }^{15}$.

Mientras JEZÉ, bajo estos presupuestos, moderaba un poco la magnitud del servicio público, al estimar que viene a ser sólo la actividad de la Administración Pública. La influencia de ese primer autor permanece, pero en una segunda noción, más restringida, del servicio público, al identificarlo sólo con las actividades de titularidad pública que tienen como objeto directo la prestación material de un servicio o de los servicios sociales stricto sensu. Es este concepto más limitado el que permite diferenciar como específica la actividad pública prestacional o

15 DUGUIT, León, Manual de Derecho Constitucional, Teoría General, del Estado, el Derecho y el Estado, las libertades públicas, organización política, traducción, con prólogo y apéndice sobre la representación proporcional por José G. Acuña, $2^{\text {da }}$ Edición Española, Imprenta de sucesores de Revadeneyra S.A, Librería Española y Extranjera Príncipe, 1926, pp.71 y ss. 
de servicio de aquellas cuyo objeto directo es la regulación, la ordenación o el control de actividades privadas o el fomento y apoyo de iniciativas privadas ${ }^{16}$.

Un concepto más preciso es el expuesto por GARCÍA DE ENTERRÍA, al explicar el contenido de la función pública de la siguiente manera: "Las funciones públicas están a cargo de los funcionarios públicos del Estado en correspondencia con la competencia que le son atribuidas por el derecho positivo y en ejercicio del poder público"; esto enmarca la delimitación de la función pública, sin tratar de conceptualizarla en su estructura orgánica o en un grupo objetivo de acciones u omisiones ${ }^{17}$.

Pero, ¿en qué grado son responsables quienes prestan servicios públicos o realizan actos administrativos o celebran contratos públicos a nombre del Estado y de las Instituciones Públicas Estatales o Autónomas?

Es menester, antes de dar respuesta a esta interrogante, definir que en el ámbito extracontractual existen varios tipos de responsabilidades, por lo que en términos generales encontraremos la responsabilidad civil siempre que una persona deba reparar un daño que ha producido a otra.

La responsabilidad penal cuando se cometa un delito o cuasidelito penal y por último ante la Responsabilidad Administrativa o del Estado, cuando una persona sea lesionada en sus derechos por la Administración del Estado, de sus organismos o de las municipalidades.

Es necesario dejar sentado que este ensayo dirige su estudio en especial a la responsabilidad administrativa o del Estado, toda vez que el Estado está al servicio de la persona humana, es decir, tiene un fin y ese fin es el respeto del hombre en toda su amplitud y para alcanzar dicho objetivo algunas veces puede dañar a los propios administrados en la consecución del mismo.

\section{¿Pero por qué debe reparar los perjuicios que cause a sus administrados?}

Para DROMI el Estado debe responder porque es un sujeto con una personalidad jurídica y política, por lo que debe someterse y responder

16 JÉZE, Gastón, Los Principios Generales del Derecho Administrativo, Tomo II, Editorial Depalma, Buenos Aires, 1949, pp.4-38.

17 GARCÍA DE ENTERRÍA, Eduardo y FERNÁNDEZ Tomás, Ramón, Curso de Derecho Administrativo, Tomo I, $6^{\text {ta }}$ Edición, Editorial Civitas, S.A., Madrid, 1993, p.24. 
como cualquier otro sujeto jurídico ante el imperio del Derecho; los administrados tienen derechos subjetivos reconocidos por el Estado, lo que da nacimiento a una relación jurídico administrativa entre el Estado y los particulares, en la que cada uno tendrá derechos y deberes, y en el caso de incumplimiento de los mismos, serán castigados con una sanción y deberán reparar el daño cometido.

Es por ello que se reconoce que hoy constituye el avance más importante dentro de la evolución de la responsabilidad del Estado, el Estado que era arrogante e irresponsable pasa a convertirse en un Estado responsable jurídicamente ante los administrados y éste logro es posible gracias a la consolidación de un Estado de Derecho. La responsabilidad se hará valer tímidamente en un comienzo mediante la responsabilidad por el hecho ajeno, consagrada en el Derecho Civil (responsabilidad indirecta del Estado).

En todo este análisis son considerados funcionarios públicos aquellos que se desempeñan en cargos electivos dentro del Estado (éstos tienen responsabilidad penal, civil y administrativa) o cualquier otro empleado que cumpla funciones públicas, ya sea de modo gratuito $\mathrm{u}$ oneroso, sin importar jerarquía, aunque algunos podrán alegar que cumplieron órdenes superiores si se hallan en una jerarquía donde solo ejecutan órdenes, careciendo de capacidad decisoria.

Es apreciado por este autor cómo ciertos funcionarios públicos, con responsabilidad política, en Argentina, pueden ser sometidos a juicio político, como el Presidente, el Vicepresidente, Ministros, Jefe de Gabinete, y miembros de la Corte Suprema de justicia. Los Senadores y Diputados pueden ser sometidos a desafuero para luego serjuzgados.

En general, tienen responsabilidad administrativa por el incumplimiento de los deberes que le son propios en el cargo que desempeñan, y una responsabilidad penal, ya que ciertos delitos requieren, para configurar el tipo penal, que el sujeto activo sea un funcionario público, como ocurre con el cohecho, el abuso de autoridad, la malversación de caudales públicos (peculado), el prevaricato o las exacciones ilegales.

Con respecto a la responsabilidad civil de los funcionarios públicos, el Código Civil no les atribuye la misma que la de cualquier otra persona, de tener que reparar los daños y perjuicios que ocasionen por sus hechos $\mathrm{u}$ omisiones culposas o dolosas, cumpliendo de modo irregular sus funciones. 
La responsabilidad de estos funcionarios es personal, y su propio patrimonio se verá afectado, salvo que cumplieran sus funciones de acuerdo a lo normado y a pesar de ello se haya causado el perjuicio, en cuyo caso responderá el Estado.

A todo lo antes enunciado podemos referir que una Administración "responsable" frente al ciudadano, se consagra por cuantas actuaciones realice en su cometido de servir con objetividad a los intereses generales. No obstante, los medios para asegurar el sometimiento de la Administración a la legalidad, así como la garantía de la defensa frente a los eventuales abusos administrativos no se agotan en la fiscalización que se pueda hacer en la jurisdicción contencioso-administrativa frente a los actos y normas que de ella dimanen ${ }^{18}$.

Junto con el control y la revisión judicial de los actos emanados de la Administración, coexiste la responsabilidad funcionarial; tanto la disciplinaria, vinculada a la exigencia del buen funcionamiento de la gestión administrativa, como la responsabilidad patrimonial, exigible por la vía civil, y la responsabilidad penal, esto como salvaguarda del prestigio y dignidad de la Administración y garantía de la correcta actuación de los funcionarios.

Respecto del fundamento o naturaleza jurídica del régimen disciplinario se aprecia cómo se ha discutido desde el plano doctrinal de forma muy extensa y contradictoria. La responsabilidad disciplinaria se proyecta sobre la actuación del personal al servicio de la Administración en el marco de la relación de servicio público, garantizando el cumplimiento de los deberes y obligaciones de los empleados públicos mediante la imposición de sanciones que afectan a sus derechos ${ }^{19}$.

\section{ASIDERO JURÍDICO EN EL DERECHO COMPARADO S O B R E L A INS T I T U C I ÓN JURÍD I C A D E LA RESPONSABILIDAD Y SU TRATAMIENTO JURÍDICO}

En un análisis dentro del Derecho comparado se toman como referentes a países de América Latina, por la tendencia histórica, el origen 18 El recurso contencioso-administrativo se interpone por las personas naturales o jurídicas contra los
reglamentos, actos y resoluciones de la Administración Pública o de las personas jurídicas semipúblicas, que
causen estado, y vulneren un derecho o interés directo del demandante. También puede interponerse el recurso
contencioso-administrativo contra resoluciones administrativas que lesionen derechos particulares
establecidos o reconocidos por una ley, cuando tales resoluciones hayan sido adoptadas como consecuencia
de alguna disposición de carácter general, si con esta se infringe la ley en la cual se originan aquellos derechos.
19 DELGADILLO GUTIÉRREZ, Luis, El sistema de responsabilidades de los servidores públicos, $6^{\text {ta }}$
edición, Editorial Porrúa, México, 2011; MARTÍNEZ MARÍN, Antonio, Régimen Jurídico de los
funcionarios, $2^{\text {da }}$ edición, actualizada y completada, Editorial Tecnos, Madrid, 2001; IVANEGA, Miriam, La
responsabilidad de los funcionarios públicos, Estudios de Derecho Público, Editorial Facultad de Derecho y
Ciencias Sociales, Argentina, 2013.
96 
idiomático, las características normativas sobre la institución jurídica estudiada de la Responsabilidad, y en este contexto que se define por funcionario público y sus responsabilidades como aparecen establecidas a partir de los textos constitucionales.

\section{BOLIVIA}

Regula en el artículo 45.- Todo funcionario público, civil, militar o eclesiástico está obligado, antes de tomar posesión de un cargo público, a declarar expresa y específicamente los bienes o rentas que tuviere, que serán verificados en la forma que determine la ley.

\section{CHILE}

Se dispone en el Artículo 38.- Cualquier persona que sea lesionada en sus derechos por la Administración del Estado, de sus organismos o de las municipalidades, podrá reclamar ante los tribunales que determine la ley, sin perjuicio de la responsabilidad que pudiere afectar al funcionario que hubiere causado el daño.

\section{COLOMBIA}

Se establece a partir del Artículo 83.- Las actuaciones de los particulares y de las autoridades públicas deberán ceñirse a los postulados de la buena fe, la cual se presumirá en todas las gestiones que aquellos adelanten ante éstas.

Artículo 124.- La ley determinará la responsabilidad de los servidores públicos y la manera de hacerla efectiva.

Artículo 130.- Habrá una Comisión Nacional del Servicio Civil responsable de la administración y vigilancia de las carreras de los funcionarios públicos, excepción hecha de las que tengan carácter especial.

Artículo 211.- La ley señalará las funciones que el Presidente de la República podrá delegar a sus ministros, directores de departamentos administrativos, representantes legales de entidades descentralizadas, superintendentes, gobernadores, alcaldes y agencias del Estado que la misma ley determine. Igualmente, fijará las condiciones para que las autoridades administrativas puedan delegar en sus subalternos o en otras autoridades. 
La delegación exime de responsabilidad al delegante, la cual corresponderá exclusivamente al delegatario, cuyos actos o resoluciones podrán siempre reformar o revocar aquel, reasumiendo la responsabilidad consiguiente.

La ley establecerá los recursos que se pueden interponer contra los actos de los delegatarios.

\section{COSTARICA}

Se establece en el Artículo 194.- El juramento que deben prestar los funcionarios públicos, según lo dispuesto en el artículo 11 de esta Constitución es el siguiente:

"-¿Juráis a Dios y prometéis a la Patria, observar y defender la Constitución y las leyes de la República, y cumplir fielmente los deberes de vuestro destino?

- Si juro

-Si así lo hiciereis, Dios os ayude, y si no, El y la Patria os lo demanden".

CUBA

Aparece regulado en el Artículo 10.- Todos los órganos del Estado, sus dirigentes, funcionarios y empleados, actúan dentro de los límites de sus respectivas competencias y tienen la obligación de observar estrictamente la legalidad socialista y velar por su respeto en la vida de toda la sociedad.

\section{EL SALVADOR}

Artículo 235.- Todo funcionario civil o militar, antes de tomar posesión de su cargo, protestará bajo su palabra de honor, ser fiel a la República, cumplir y hacer cumplir la Constitución, ateniéndose a su texto cualesquiera que fueren las leyes, decretos, órdenes o resoluciones que la contraríen prometiendo, además, el exacto cumplimiento de los deberes que el cargo le imponga, por cuya infracción será responsable conforme a las leyes.

Artículo 245.- Los funcionarios y empleados públicos responderán personalmente y el Estado subsidiariamente, por los daños materiales o morales que causare a consecuencia de la violación a los derechos consagrados en esta Constitución. 


\section{GUATEMALA}

Artículo 155.- Responsabilidad por infracción a la ley. Cuando un dignatario, funcionario o trabajador del Estado, en el ejercicio de su cargo, infrinja la ley en perjuicio de particulares, el Estado o la institución estatal a quien sirva, será solidariamente responsable por los daños y perjuicios que se causaren.

La responsabilidad civil de los funcionarios y empleados públicos podrá deducirse mientras no se hubiere consumado la prescripción, cuyo término será de veinte años.

La responsabilidad criminal se extingue, en este caso, por el transcurso del doble del tiempo señalado por la ley para la prescripción de la pena.

Ni los guatemaltecos ni los extranjeros, podrán reclamar al Estado, indemnización por daños o perjuicios causados por movimientos armados o disturbios civiles HONDURAS

Artículo 321.- Los servidores del Estado no tienen más facultades que las que expresamente les confiere la ley. Todo acto que ejecuten fuera de la ley es nulo e implica responsabilidad.

Artículo 324.- Si el servidor público en el ejercicio de su cargo, infringe la ley en perjuicio de particulares, será civil y solidariamente responsable junto con el Estado o con la institución estatal a cuyo servicio se encuentre, sin perjuicio de la acción de repetición que éstos pueden ejercitar contra el servidor responsable, en los casos de culpa o dolo. La responsabilidad civil no excluye la deducción de las responsabilidades administrativa y penal contra el infractor.

\section{MEXICO}

Artículo 108.- Para los efectos de las responsabilidades a que alude este título se reputaran como servidores públicos a los representantes de elección popular, a los miembros del poder judicial federal y del poder judicial del Distrito Federal, los funcionarios y empleados, y, en general, a toda persona que desempeñe un empleo, cargo o comisión de cualquier naturaleza en la administración pública federal o en el Distrito Federal, así como a los servidores del instituto federal electoral, quienes serán responsables por los actos u omisiones en que incurran en el desempeño de sus respectivas funciones. 
El Presidente de la República, durante el tiempo de su encargo, solo podrá ser acusado por traición a la patria y delitos graves del orden común.

Los gobernadores de los Estados, los diputados a las legislaturas locales, los magistrados de los tribunales superiores de justicia locales y, en su caso, los miembros de los consejos de las judicaturas locales, serán responsables por violaciones a esta constitución y a las leyes federales, así como por el manejo indebido de fondos y recursos federales.

Las constituciones de los estados de la República precisaran, en los mismos términos del primer párrafo de este Artículo y para los efectos de sus responsabilidades, el carácter de servidores públicos de quienes desempeñen empleo, cargo o comisión en los estados y en los municipios.

Artículo 109.- El Congreso de la Unión y las legislaturas de los Estados, dentro de los ámbitos de sus respectivas competencias, expedirán las leyes de responsabilidades de los servidores públicos y las demás normas conducentes a sancionar a quienes, teniendo este carácter, incurran en responsabilidad, de conformidad con las siguientes prevenciones:

I. Se impondrán, mediante juicio político, las sanciones indicadas en el Artículo 110 a los servidores públicos señalados en el mismo precepto, cuando en el ejercicio de sus funciones incurran en actos $u$ omisiones que redunden en perjuicio de los intereses públicos fundamentales o de su buen despacho. No procede el juicio político por la mera expresión de ideas.

II. La comisión de delitos por parte de cualquier servidor público será perseguida y sancionada en los términos de la legislación penal; y III. Se aplicarán sanciones administrativas a los servidores públicos por los actos u omisiones que afecten la legalidad, honradez, lealtad, imparcialidad y eficiencia que deban observar en el desempeño de sus empleos, cargos o comisiones.

Los procedimientos para la aplicación de las sanciones mencionadas se desarrollarán autónomamente. No podrán imponerse dos veces por una sola conducta sanciones de la misma naturaleza. Las leyes determinaran los casos y las circunstancias en los que se deba sancionar penalmente por causa de enriquecimiento ilícito a los servidores públicos que, durante el tiempo de su encargo, o por motivos del mismo, por si o por interpuesta persona, aumenten substancialmente su patrimonio, 100 
adquieran bienes o se conduzcan como dueños sobre ellos, cuya procedencia licita no pudiesen justificar. Las leyes penales sancionaran con el decomiso y con la privación de la propiedad de dichos bienes, además de las otras penas que correspondan.

Cualquier ciudadano, bajo su más estricta responsabilidad y mediante la presentación de elementos de prueba, podrá formular denuncia ante la Cámara de Diputados del Congreso de la Unión respecto de las conductas a las que se refiere el presente Artículo.

Artículo 110.- Podrán ser sujetos de juicio político los Senadores y Diputados al Congreso de la Unión, los ministros de la Suprema Corte de Justicia de la nación, los consejeros de la judicatura federal, los secretarios de despacho, los jefes de departamento administrativo, los diputados a la asamblea del Distrito Federal, el jefe de gobierno del Distrito Federal, el procurador general de la República, el procurador general de justicia del Distrito Federal, los magistrados de circuito y jueces de distrito, los magistrados y jueces del fuero común del Distrito Federal, los consejeros de la judicatura del Distrito Federal, el consejero Presidente, los consejeros electorales, y el secretario ejecutivo del instituto federal electoral, los magistrados del tribunal electoral, los directores generales y sus equivalentes de los organismos descentralizados, empresas de participación estatal mayoritaria, sociedades y asociaciones asimiladas a estas y fideicomisos públicos.

Los gobernadores de los Estados, diputados locales, magistrados de los tribunales superiores de justicia locales y, en su caso, los miembros de los consejos de las judicaturas locales, solo podrán ser sujetos de juicio político en los términos de este título por violaciones graves a esta constitución y a las leyes federales que de ella emanen, así como por el manejo indebido de fondos y recursos federales, pero en este caso, la resolución será únicamente declarativa y se comunicara a las legislaturas locales para que, en ejercicio de sus atribuciones, procedan como corresponda.

Las sanciones consistirán en la destitución del servidor público y en su inhabilitación para desempeñar funciones, empleos, cargos o comisiones de cualquier naturaleza en el servicio público.

Para la aplicación de las sanciones a que se refiere este precepto, la Cámara de Diputados procederá a la acusación respectiva ante la Cámara de Senadores, previa declaración de la mayoría absoluta del número de los miembros presentes en sesión de aquella cámara, después de haber sustanciado el procedimiento respectivo y con audiencia del inculpado. 
Conociendo de la acusación la Cámara de Senadores, erigida en jurado de sentencia, aplicara la sanción correspondiente mediante resolución de las dos terceras partes de los miembros presentes en sesión, una vez practicadas las diligencias correspondientes y con audiencia del acusado. Las declaraciones y resoluciones de las Cámaras de Diputados y Senadores son inatacables.

Artículo 113.- Las leyes sobre responsabilidades administrativas de los servidores públicos, determinaran sus obligaciones a fin de salvaguardar la legalidad, honradez, lealtad, imparcialidad y eficiencia en el desempeño de sus funciones, empleos, cargos y comisiones; las sanciones aplicables por los actos u omisiones en que incurran, así como los procedimientos y las autoridades para aplicarlas. Dichas sanciones, además de las que señalen las leyes, consistirán en suspensión, destitución e inhabilitación, así como en sanciones económicas, y deberán establecerse de acuerdo con los beneficios económicos obtenidos por el responsable y con los daños y perjuicios patrimoniales causados por sus actos u omisiones a que se refiere la Fracción III de Artículo 109, pero que no podrán exceder de tres tantos de los beneficios obtenidos o de los daños y perjuicios causados.

Artículo 114.- El procedimiento de juicio político solo podrá iniciarse durante el periodo en el que el servidor público desempeñe su cargo y dentro de un año después. Las sanciones correspondientes se aplicarán en un período no mayor de un año a partir de iniciado el procedimiento.

La responsabilidad por delitos cometidos durante el tiempo del encargo por cualquier servidor público, será exigible de acuerdo con los plazos de prescripción consignados en la ley penal, que nunca serán inferiores a tres años. Los plazos de prescripción se interrumpen en tanto el servidor público desempeña alguno de los encargos a que hace referencia el Artículo 111.

La ley señalara los casos de prescripción de la responsabilidad administrativa tomando en cuenta la naturaleza y consecuencia de los actos y omisiones a que hace referencia la Fracción III de Artículo 109. Cuando dichos actos $\mathrm{u}$ omisiones fuesen graves los plazos de prescripción no serán inferiores a tres años.

Artículo 128.- Todo funcionario público, sin excepción alguna, antes de tomar posesión de su encargo, prestara la protesta de guardar la Constitución y las leyes que de ella emanen. 


\section{NICARAGUA}

Se reconoce a partir del Artículo 130.- Disposiciones generales sobre el régimen económico y financiero.

Artículo 131.- Los funcionarios de los cuatro poderes del Estado, elegidos directa o indirectamente, responden ante el pueblo por el correcto desempeño de sus funciones y deben informarle de su trabajo y actividades oficiales. Deben atender y escuchar sus problemas y procurar resolverlos. La función pública se debe ejercer a favor de los intereses del pueblo.

El Estado, de conformidad con la ley, será responsable patrimonialmente de las lesiones que, como consecuencia de las acciones u omisiones de los funcionarios públicos en el ejercicio de su cargo, sufran los particulares en sus bienes, derechos e intereses, salvo los casos de fuerza mayor. El Estado podrá repetir contra el funcionario o empleado público causante de la lesión. Los funcionarios y empleados públicos son personalmente responsables por la violación de la Constitución, por falta de probidad administrativa y por cualquier otro delito o falta cometida en el desempeño de sus funciones. También son responsables ante el Estado de los perjuicios que causaren por abuso, negligencia y omisión en el ejercicio del cargo. Las funciones civiles no podrán ser militarizadas. El servicio civil y la carrera administrativa serán regulados por la ley.

PANAMA

A partir del Artículo 18.- Los particulares solo son responsables ante las autoridades por infracción de la Constitución o de la Ley. Los servidores públicos lo son por esas mismas causas y también por extralimitación de funciones o por omisión en el ejercicio de éstas.

Artículo 33.- Pueden penar sin juicio previo, en los casos y dentro de lo precisos términos de la Ley: 1. Los servidores públicos que ejerzan mando y jurisdicción, quienes pueden imponer multas o arrestos a cualquiera que los ultraje o falte al respeto en el acto en que estén desempeñando las funciones de su cargo o con motivo del desempeño de las mismas. ...

Artículo 299.- El Presidente y Vicepresidentes de la República, los Magistrados de la Corte Suprema de Justicia, de los Tribunales ordinarios y especiales, el Procurador General de la Nación y el de la Administración, los Jueces, los Ministros de Estado, el Contralor 
General de la República, el Presidente de la Asamblea Legislativa, los Directores Generales, Gerentes o jefes de entidades autónomas, los Directores Nacionales y Provinciales de los servicios de Policía, empleados o funcionarios públicos de manejo conforme al Código Fiscal, deben presentar al inicio y término de sus funciones, una declaración jurada de su estado patrimonial, la cual deberán hacer en un término de diez días hábiles a partir de la toma de posesión del cargo y diez días hábiles a partir de la separación.

El Notario realizará esta diligencia sin costo alguno. Esta disposición tiene efectos inmediatos, sin perjuicio de su reglamentación por medio de Ley.

\section{PARAGUAY}

Se regula a partir del Artículo 104.- DE LA DECLARACIÓN OBLIGATORIA DE BIENES Y RENTAS. Los funcionarios y los empleados públicos, incluyendo a los de elección popular, los de entidades estatales, binacionales, autárquicas, descentralizadas y, en general, quienes perciban remuneraciones permanentes del Estado, estarán obligados a prestar declaración jurada de bienes y rentas dentro de los quince días de haber tomado posesión de su cargo, y en igual término al cesar en el mismo.

Artículo 106.- DE LA RESPONSABILIDAD DEL FUNCIONARIO Y DEL EMPLEADO PÚBLICO. Ningún funcionario o empleado público está exento de responsabilidad. En los casos de transgresiones, delitos o faltas que cometiesen en el desempeño de sus funciones, son personalmente responsables, sin perjuicio de la responsabilidad subsidiaria del Estado, con derecho de éste a repetir el pago de lo que llegase a abandonar en tal concepto.

\section{PERU}

Artículo 41.- Los funcionarios y servidores públicos que señala la ley o que administran o manejan fondos del Estado o de organismos sostenidos por éste deben hacer declaración jurada de bienes y rentas al tomar posesión de sus cargos, durante se ejercicio y al cesar los mismos. La respectiva publicación se realiza en el diario oficial en la forma y condiciones que señala la ley.

Cuando se presume enriquecimiento ilícito, el Fiscal de la Nación, por denuncia de terceros o de oficio, formula cargos ante el Poder Judicial. 
La ley establece la responsabilidad de los funcionarios y servidores públicos, así como el plazo de su inhabilitación para su la función pública.

El plazo de prescripción se duplica en caso de delitos cometidos contra el patrimonio del Estado.

\section{REPÚBLICA DOMINICANA}

Artículo 102.- Será sancionado con las penas que la ley determine, todo aquel que, para su provecho personal, substraiga fondos públicos o prevaleciéndose de sus posiciones dentro de los organismos del Estado, sus dependencias o instituciones autónomas, obtenga provechos económicos. Serán igualmente sancionadas las personas que hayan proporcionado ventajas a sus asociados, familiares, allegados, amigos o relacionados. Nadie podrá ser penalmente responsable por el hecho de otro ni en estos casos ni en cualquier otro.

Artículo 106. -La persona designada para ejercer una función pública deberá prestar juramento de respetar la Constitución y las leyes, y de desempeñar fielmente su cometido. Este juramento se prestará ante cualquier funcionario u oficial público.

\section{URUGUAY}

Artículo 24.- El Estado, los Gobiernos Departamentales, los Entes Autónomos, los Servicios Descentralizados y, en general, todo órgano del Estado, serán civilmente responsables del daño causado a terceros, en la ejecución de los servicios públicos, confiados a su gestión o dirección.

Artículo 25.-Cuando el daño haya sido causado por sus funcionarios, en el ejercicio de sus funciones o en ocasión de ese ejercicio, en caso de haber obrado con culpa grave o dolo, el órgano público correspondiente podrá repetir contra ellos, lo que hubiere pagado en reparación.

Artículo 64.- La ley, por dos tercios de votos del total de componentes de cada Cámara, podrá establecer normas especiales que por su generalidad o naturaleza sean aplicables a los funcionarios de todos los Gobiernos Departamentales y de todos los Entes Autónomos, o de algunos de ellos, según los casos.

Artículo 65.-La ley podrá autorizar que en los Entes Autónomos se constituyan comisiones representativas de los personales respectivos, con fines de colaboración con los Directores para el cumplimiento de las 
reglas del Estatuto, el estudio del ordenamiento presupuestal, la organización de los servicios, reglamentación del trabajo y aplicación de las medidas disciplinarias.

En los servicios públicos administrados directamente o por concesionarios, la ley podrá disponer la formación de órganos competentes para entender en las desinteligencias entre las autoridades de los servicios y sus empleados y obreros; así como los medios y procedimientos que pueda emplear la autoridad pública para mantener la continuidad de los servicios.

Artículo 66.-Ninguna investigación parlamentaria o administrativa sobre irregularidades, omisiones o delitos, se considerará concluida mientras el funcionario inculpado no pueda presentar sus descargos y articular su defensa.

\section{VENEZUELA}

Artículo 139.- El ejercicio del Poder Público acarrea responsabilidad individual por abuso o desviación de poder o por violación de esta Constitución o de la ley.

Artículo 140.- El Estado responderá patrimonialmente por los daños que sufran los particulares en cualquiera de sus bienes y derechos, siempre que la lesión sea imputable al funcionamiento de la administración pública.

Artículo 143. Los ciudadanos y ciudadanas tienen derecho a ser informados e informadas oportuna y verazmente por la Administración Pública, sobre el estado de las actuaciones en que estén directamente interesados e interesadas, y a conocer las resoluciones definitivas que se adopten sobre el particular. Asimismo, tienen acceso a los archivos y registros administrativos, sin perjuicio de los límites aceptables dentro de una sociedad democrática en materias relativas a seguridad interior y exterior, a investigación criminal y a la intimidad de la vida privada, de conformidad con la ley que regule la materia de clasificación de documentos de contenido confidencial o secreto. No se permitirá censura alguna a los funcionarios públicos o funcionarias públicas que informen sobre asuntos bajo su responsabilidad.

Este autor considera pertinente anotar que todo el análisis dentro del contexto del ensayo jurídico demuestra que el tratamiento de la responsabilidad como institución jurídica tiene su principal asidero a 106 
partir de los textos constitucionales de América Latina, factor que ha permitido el posterior desarrollo normativo dentro de los ordenamientos jurídicos ${ }^{20}$ en cada nación en cuerpos jurídicos por su especialidad, que en el caso del Ecuador así se contextualiza, y que a futuro pueda evolucionar en relación con las nuevas tendencias que en el siglo XXI aparecen en el Derecho Administrativo.

Ahora bien, en el caso específico del desarrollo de la institución jurídica de la responsabilidad dentro del ordenamiento jurídico del Ecuador, este autor justiprecia que son determinadas por dos Órganos Superiores de Control como principal característica, uno es el Congreso Nacional que, a más de tener la facultad privativa de legislar, tiene la facultad de controlar y determinar responsabilidades a los dignatarios (Presidente y Vicepresidente de la República, Ministros de Estado, Ministro Fiscal, Defensor del Pueblo, etc.), a funcionarios y a empleados públicos. Este tipo de control que se realiza y de la determinación de responsabilidades se le llama político, porque termina en un enjuiciamiento de jurisdicción privativa de la Función Ejecutiva.

El otro Órgano de Control Superior que se aprecia en el contexto ecuatoriano, es la Contraloría General del Estado, la cual ejecuta el control técnico, con base en el plan de auditorías internas y externas, mediante informes y exámenes que este ejecuta a los sujetos de control (personas jurídicas y naturales).

Se demuestra otra de sus características que lo definen, su desarrollo se ha materializado en este orden en la Constitución Política, en la Ley Orgánica de la función legislativa en la nación del Ecuador, y en la Ley Orgánica del Sistema Nacional de Control y de la Contraloría General de la República. Sirva entonces este ensayo para aportar una caracterización de los elementos teóricos y normativos de la responsabilidad de los funcionarios públicos en su actuación como servidores públicos de la Administración Pública, ante las exigencias que impone el ordenamiento jurídico actual, considerando la interrelación con el Derecho Público, con una primigenia valoración histórica y doctrinal.

\section{CONCLUSIONES}

El concepto de funcionario público está ligado al Estado, condicionado a su historia y a su legislación y varía según mutan las características de la Administración Pública y la modalidad de las prestaciones que realiza.

20 SANTI, Romano, El ordenamiento jurídico, Editorial Instituto de Estudios Políticos, Madrid, 1963; ATIENZA, Manuel, Argumentación y legislación, Editorial Thomson Civitas, Madrid, 2004 
La determinación de responsabilidades, tanto políticas como técnicas, está definida en el Ecuador por la Constitución y por las Leyes de Control Administrativo como una de sus características, en cuanto a su definición legal, sus sanciones y funcionarios facultados para resolver sobre ellas. Los funcionarios públicos responden sobre la responsabilidad en que incurran en materia civil, administrativa y penal.

En Ecuador existen dos órganos superiores de control, uno es el Congreso Nacional y el otro es la Contraloría General del Estado, como otra característica que le definen. Su materialización en el ordenamiento jurídico se instituye a partir del texto constitucional y su desarrollo normativo se regula en la Ley orgánica de la función legislativa de la nación.

En Ecuador, se deberá pensar en la participación y control social, permitirá contribuir al fortalecimiento de las capacidades de los actores del control social para un mejor ejercicio del mismo, en los procesos de rendición pública de cuentas y su articulación con el control gubernamental y cumplir los objetivos de gestión, la ejecución física y financiera del presupuesto.

\section{REFERENCIAS BIBLIOGRÁFICAS}

AA. VV. Estudios cubanos sobre el control de la constitucionalidad, MATILlA CORREA, Andry (compilador), Editorial Porrúa, México, 2009.

ATIENZA, Manuel, Argumentación y legislación, Editorial Thomson Civitas, Madrid, 2004.

ARIAS GAYOSO, Grethel, Del nuevo Derecho Administrativo: Participación y control popular en la gestión pública. Participación Política, reflexiones desde el Sur, Tomo II, $1^{\text {ra }}$ edición, Editorial Advantlogic, Ecuador, 2014.

BIELSA, Rafael, Derecho Administrativo, Tomos II y III, $3^{\text {ra }}$ Edición, Editorial DEPALMA, Buenos Aires, 1956.

BIELSA, Rafael, La función pública, Buenos Aires, 1966.

BIELSA, Rafael, Los agentes de la Administración Pública, funcionarios y empleados, Editorial Roque de Palma, Buenos Aires, 1956. 
CASSAGNE, Juan Carlos, Derecho Administrativo, Tomo I, $6^{\text {ta }}$ Edición, Editorial Abeledo- Perrot, Buenos Aires, 2002.

CAGNONI, José, Introducción a la Teoría del Control, Editorial Universidad de Montevideo, Uruguay, 1996.

CORDERO VEGA, Luis, El Control de la Administración del Estado, Editorial Lexis Nexis, Chile, 2007.

COOPERS \& LYBRAND, Los nuevos conceptos del control interno (Informe COSO), Díaz de Santos, Madrid, 1997.

DE MIGUEL, Raimundo, Diccionario etimológico latino-español, $23^{\text {ra }}$ edición, Madrid, 1974.

DELPIAZZO RODRÍGUEZ, Carlos, Desafios actuales del control, Editorial FCU, Montevideo, 2001.

DUGUIT, León, Las transformaciones del Derecho Público, Traducción con estudio preliminar de Adolfo Posada y Ramón Jaén, $2^{\text {da }}$ Edición, Librería Española y Extranjera, Madrid.

DELGADILLO GUTIÉRREZ, Luis, El sistema de responsabilidades de los servidores públicos, $6^{\text {ta }}$ edición, Editorial Porrúa, México, 2011.

DROMI, Roberto, Modernización del Control Público, Editorial Hispania Libros, Madrid, 2005.

DROMI, Roberto, Derecho subjetivo y responsabilidad pública, Editorial Temis, Bogotá, 1980.

GARCÍA DE ENTERRÍA, Eduardo, Curso de Derecho Administrativo, tomos I y II, 10 ${ }^{\mathrm{ma}}$ edición, Editorial Thompson-Civitas, España, 2006.

GARCÍA DE ENTERRÍA, Eduardo, La administración y sus agentes, la administración española, Editorial Alianza, Madrid, 1972.

GARRIDO FALLA, Fernando, PALOMAR OLMEDA, Alberto, LOSADA GONZÁLEZ, Herminio, Tratado de Derecho Administrativo, Tomo I, parte general, $14^{\text {ce }}$ Edición, Editorial Tecnos, Madrid, 2005. 
GIMÉNEZ ICARRONS, Eugenia, Los controles administrativos sobre los entes locales, Generalitat de Catalunya, Institut d'Estudis Autonómics-Marcial Pons, Editorial Jurídicas y Sociales S.A, Madrid, 2001.

GORDILLO, Agustín, Tratado de Derecho Administrativo, Tomo II, Parte General, $8^{\text {va }}$ Edición, Editorial Fundación de Derecho Administrativo, Buenos Aires, 2003.

MATILlA CORREA, Andry, Derecho Administrativo y servicio público. Trazos inconclusos desde una perspectiva histórica en, Revista Jurídica, México, 2014,pp. 383-449.

MARTÍN-RETORTILlO BAQUER, Lorenzo, Poder Ejecutivo, discrecionalidad, legalidad y control, Revista del Poder Judicial, número 6, Consejo General del Poder Judicial, Madrid, 1997.

MARTÍNEZ MARÍN, Antonio, Régimen Jurídico de los funcionarios, $2^{\text {da }}$ edición, actualizada y completada, Editorial Tecnos, Madrid, 2001.

MÁRQUEZ GÓMEZ, Daniel, Los Procedimientos Administrativos materialmente jurisdiccionales como medios de control en la Administración Pública, Universidad Nacional Autónoma de México, México, 2002.

MARIENHOFF, Miguel, Tratado de Derecho Administrativo, Tomo III, $3^{\text {ra }}$ edición actualizada, Editorial Abeledo-Perrot, Buenos Aires, 1965.

SANTI, Romano, El ordenamiento jurídico, Editorial Instituto de Estudios Políticos, Madrid, 1963.

SÁNCHEZ MORÓN, Miguel, Derecho de la función pública, Editorial Tecnos, España, 2008.

SÁNCHEZ MORÓN, Miguel, El control de las Administraciones Públicas y sus problemas, Editorial Espasa- Calpe S.A, Madrid, 1991.

SÁNCHEZ MORÓN, Miguel, La participación del ciudadano en la Administración Pública, Editorial CEC, Madrid, 1980. 
SORIANO GARCÍA, José, El Derecho Administrativo y los desafios del siglo XXI, Editorial Aranzadi, España, 2011, pp. 1-29.

IVANEGA, Miriam, La responsabilidad de los funcionarios públicos, Estudios de Derecho Público, Editorial Facultad de Derecho y Ciencias Sociales, Argentina, 2013.

RIVERO ORTEGA, Ramón, El Estado vigilante, Editorial Tecnos, Madrid, 2000.

ROZA FLORES, Alan, El impacto social del control público en el Perú, Tesis Doctoral Universidad Nacional Mayor de San Marcos, Perú, 2013.

JÉZE, Gastón, Principios Generales del Derecho Administrativo, Tomo II, Editorial Depalma, Buenos Aires, 1949.

JEZE, Gastón, Técnica jurídica, servicio, función pública y sus servidores, Editorial jurídica Universitaria, México, 2007.

OYANGUREN, Armando, Manual elemental de Derecho Administrativo, Editorial Universitaria de la UNAN, Nicaragua, 1992.

PARADA, Ramón, Derecho Administrativo, tomo I, $9^{\text {na }}$ edición, Editorial Marcial Pons, España, 1997.

PALOMAR OLMEDA, Alberto, Derecho de la Función Pública, $4^{\text {ta }}$ edición, Editorial Dykinson, Barcelona, 1997.

POSADA, Adolfo, Tratado de Derecho Administrativo, tomo I, $2^{\text {da }}$ edición, Editorial Madrid, España, 1931.

VÁZQUEZ ALFARO, José Luis, El control de la Administración Pública en México, Universidad Nacional Autónoma de México, México, 1996.

VÁZQUEZ-PORTOMEÑE SEIJAS, Fernando, Los delitos contra la Administración Pública. Teoría General, Editorial Instituto Nacional de Administración Pública, Santiago de Compostela, Madrid, 2003. 
VALADÉS, Diego, El control del Poder, Biblioteca Jurídica VirtualUNAM, México, 2011.

Disposiciones jurídicas

Constitución de la República del Ecuador,

Ley $N^{\circ}$ 0, Ley Orgánica del Servicio Público, 6 de octubre de 2010. Copia certificada del oficio No. T.1919 SNJ-10-1479 de 4 de octubre de 2010.

Ley $\mathrm{N}^{0}$ 27785, Ley Orgánica del Sistema Nacional de Control y de la Contraloría General de la República. 